\title{
Complaint Management System for Sarawak Rural Area Water Supply Department
}

\author{
SELINA LUAT \& EMMY HOSSAIN* \\ Faculty of Computer Science and Information Technology, Universiti Malaysia Sarawak, 94300 Kota \\ Samarahan, Sarawak, Malaysia \\ *Corresponding authors: hedahliana@unimas.my
}

\begin{abstract}
This Complaint Management System is developed to manage the complaints received by the Corporate Communication Unit of the Sarawak Rural Area Water Supply Department. This system was developed to solve the current problems faced in managing, retrieving and updating data using the manual method by the Department. Users of the system are the administrative staff and division water engineers. Users are able to add, update and delete complaint records, as well as view information in graphical format such as pie charts and graphs. Rapid Application Development (RAD) was used to develop this system, consisting of four phases: analysing user requirement, develop a prototype, construction and cut over. The feedback received from the Department's staff is positive and showed that the users are satisfied with the system developed.
\end{abstract}

Keywords: Complaint management system, Rapid Application Development, Sarawak Rural Water Supply Department

Copyright: This is an open access article distributed under the terms of the CC-BY-NC-SA (Creative Commons Attribution-NonCommercial-ShareAlike 4.0 International License) which permits unrestricted use, distribution, and reproduction in any medium, for non-commercial purposes, provided the original work of the author(s) is properly cited.

\section{INTRODUCTION}

The Sarawak Rural Area Water Supply Department, formerly known as Jabatan Kerja Raya Water Supply Authorities was launched on 1st of September 2015 where this department had been operating for the last five years (Sarawak Rural Water Supply Department, 2020). This department is under the purview of the Ministry of Public Utilities. The Permanent Secretary of the Ministry of Public Utilities has assigned as the State Water Authority under the provisions of the Water Ordinance 1994 which allowed the establishment of various Water Supply Authorities under Jabatan Kerja Raya to supply drinkable water. The Corporate Communication Unit is a unit under the Corporate Communications and Digitalization Department at Sarawak Rural Area Water Supply Department (Headquarters). This unit is also known as the Public Relations Unit since the unit is as an intermediary between Sarawak Rural Area Water Supply with their customers. The Corporate Communication Unit receives complaints every day regarding water supply problems via telephone calls from customers all over Sarawak. Every complaint received will be written on paper and then typed into Microsoft Excel.

A report will be generated for each complaint received and the report will be sent to the Division Water Engineer or Assistant Division Water Engineer for further action. Other than that, for yearly report, they have to present statistics for complaints that they received since the beginning of the year. Web-based system is a system that uses web technologies to improve customer service and keep customer data in a centralized location. Managing complaints for different cases and locations is quite difficult due to the manual way of doing this (writing on paper), with no centralized web-based system to manage the workflow. These problems inspired the department to have a new complaint management system which will be more convenient to use. This system allows all complaints data to be keyed in and stored in a web-based system for systematic managing and handling of the complaints. Since the establishment of Sarawak Rural Area Water Supply Department, the Corporate Communication Unit does not have any proper computer-based system for the complaints received. Every complaint received will be recorded manually on a Customer Complaints Form and will be simply converted into Microsoft Excel which is then rearranged according to division. Then, they have to create another Excel to create the yearly report and sort the cases by case category. Problems arise when forms are misplaced and this can affect 
the result of the statistics for the yearly report. Complaints' case category that is not recorded in a proper way will also affect the statistics. Human error and data redundancy can also happen when complaints are done manually. Any complaints received regarding water issues via telephone is directed to 082-263000, but the info is not sent directly to the Division Head Office; the Corporate Communication Unit has to do a report about the complaints and then inform the Division Water Engineer through text messages or WhatsApp. Problems arise when most of the information is misread by the engineer. The water supply problem may continue as sometimes the officer might forget to remind the Division Water Engineer due to other commitments; and subsequently the customer may get angry and post about the issue on social media and in press statements. This could ruin the organization's reputation.

The Complaint Management System is proposed to manage the complaints according to division and cases. This system is able to add, edit, delete and search cases. Apart from that this system is also able to display filtered tables and statistics in the form of graphs. The other purpose of this system is to enable the checking of the progresses of complaint cases being reported - from the start of the complaint until the case is closed. The cases can also be filtered by division, therefore the most frequent division that faces water supply problems can be identified. Subsequently, the water supply system for all divisions in Sarawak can be improved. Moreover, it is a more systematic way to manage complaints, retrieve data and obtained results for the recorded data by the department staff.

\section{METHODOLOGY}

The methodology that has been chosen to develop this system is Rapid Application Development (RAD). There are four phases during to develop this project using RAD, which are Requirement Planning, User Design, Construction and Cutover (Miller, 2018). The tasks, tools, and techniques used during the RAD phases are shown in Figure 1.

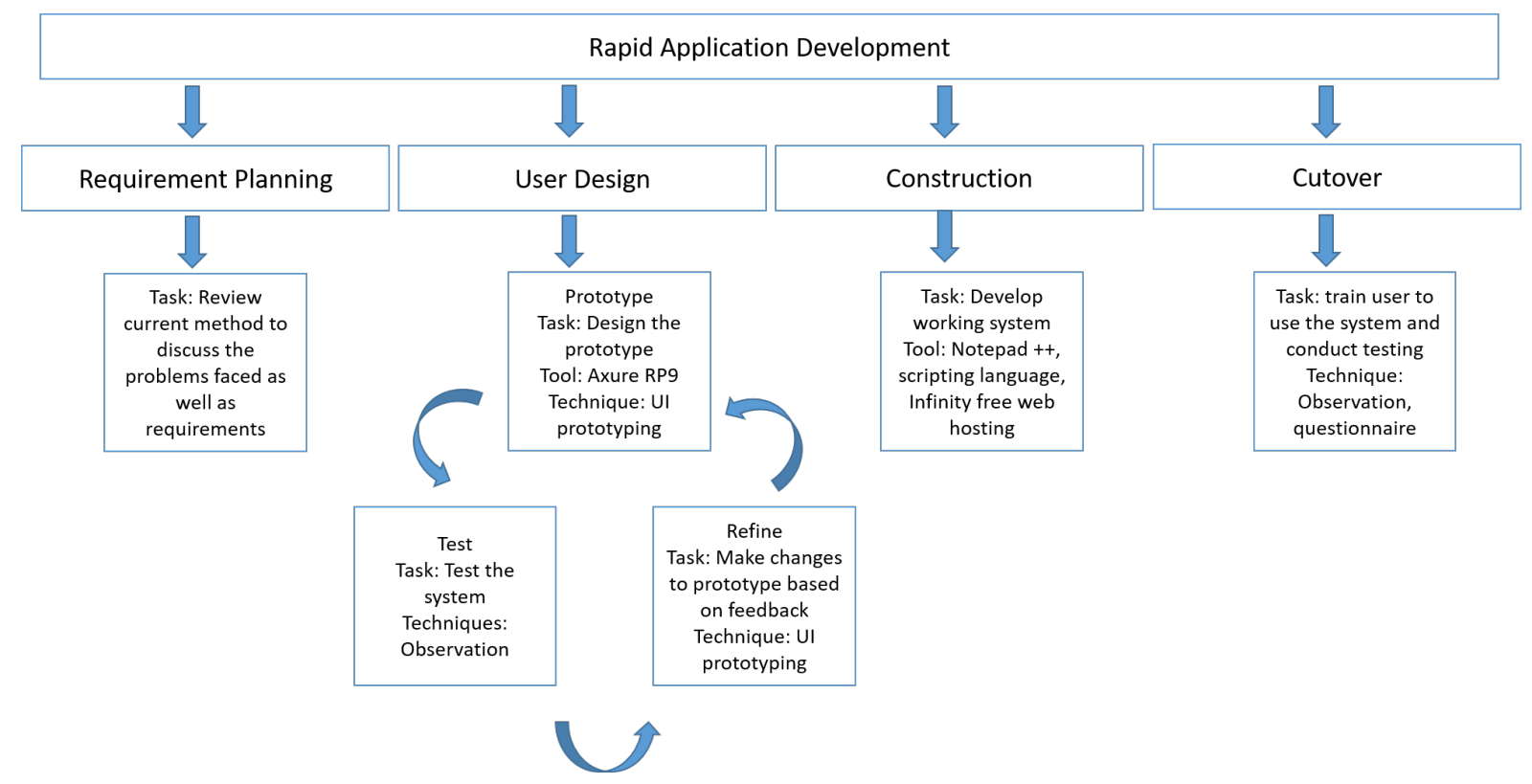

Figure 1. Project methodology diagram (Luat, 2020) 


\section{i. Requirement Planning}

This phase is for the developer and client to create the project vision that will become the inspiration and gives focus or guidelines for the entire project. During this phase, the current method was reviewed to know the problems that are faced by the Corporate Communication Unit on managing complaints. In order to gather information, a survey questionnaire was distributed to the client (Corporate Communication Unit staff) focusing on their constraints in using the current method and to discover the features that an online complaint management system should have. Survey results were revised to obtain the user requirements for the complaint management system. The Corporate Communication Unit needs a web-based system where complaints that are reported will be stored and managed. The system is also able to display graphs for cases by month according to division and analysis, as well as case progression monitoring. At the end of this phase, the client and developer need to have goals and expectations for the project which include all the user requirements.

\section{ii. User Design}

The User design phase is where the developer and client work together to ensure the goal and requirement meets users need. The developer has to design a prototype with features that are needed by the client. The features and requirements obtained from the previous phase were designed during this phase. The User Design phase consists of three tasks which are prototyping, test and refine.

\section{Prototyping}

The developer designed the prototype based on the features and requirements that users need. The prototype will become the guideline for the developer to develop the real system. This prototype was tested by the client who gave review and feedback.

Test

Clients tested the system and noted any new ideas or changes if there were any features and requirements that needed to be included in the system. The prototype flow was discussed to ensure the system was easy to use.

\section{Refine}

During refining, changes will be made according to the feedback received to ensure that the system meets user requirements and expectations. If the client is satisfied with the changes, the next phase will start immediately.

\section{iii. Construction}

Construction phase is the development phase where the real system will be built. The prototype that was built in the previous phase was used as a guideline to develop the working model. Changes and new ideas could still be added to the system during this phase. The developer begun scripting for the system based on the prototype. This scripting process was to create the interface for HTML and PHP using Notepad ++. Database was constructed using Xampp. Cascading Style Sheets (CSS) was used to design the interface. At the end of this phase, the system should be able to be used, which means it is a complete system and that it is ready to be deployed. The system was tested to make sure all the requirements were included.

\section{iv. Cutover}

For the final phase, user training will be conducted before the system is used. Users were trained to make sure that they were able to adapt to the system and to avoid confusion. The existing data that were recorded in the Excel documents before this system was developed, was loaded into the new system. Another round of testing was conducted to make sure that the system worked as expected. After this, the system was ready to be deployed to the users.

\section{RESULTS}

The Complaint Management System for Sarawak Rural Area Water Supply Department is a web-based system that was developed using scripting in PHP, HTML and CSS. All the PHP files were connected to the MYSQL for 
storing data to the MYSQL Databases. There are two types of user using this system, which are the Corporate Communication Unit staff (known as Staff user) and Division Water Engineer (known as Engineer user).

Once the user has successfully accessed the system, the user will directly enter the main page as in Figure 2 below. There are eight options of action the Staff user can perform in the system, as shown in Figure 2. The Profile button will navigate the user to their profile page that will display user information, Add User button will navigate user to the Register New User page, the Add Complaint button will navigate user to the Add New Complaint page to register new complaint to the system, the Manage Complaint button will navigate user to the Manage Complaint page to manage complaints recorded, the Reminder button will navigate the user to the Create Reminder page for staff to give reminder to the Division Water Engineer, the Case Status button will navigate the user to case status page that will display case status in the form of a pie chart (Figure 3), the Complaint Summary button will navigate the user to the Complaint Summary page which displays records in tables with filter function and lastly, the Graph Analysis button will navigate the user to the Graph and Analysis page that will display complaint records in the form of a graph. This page also has a logout button for the user to exit the system.

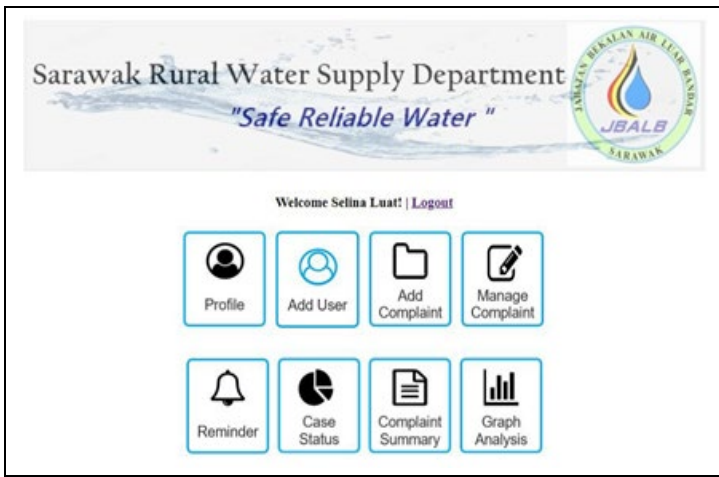

Figure 2. Main Page for Staff (Luat, 2020)

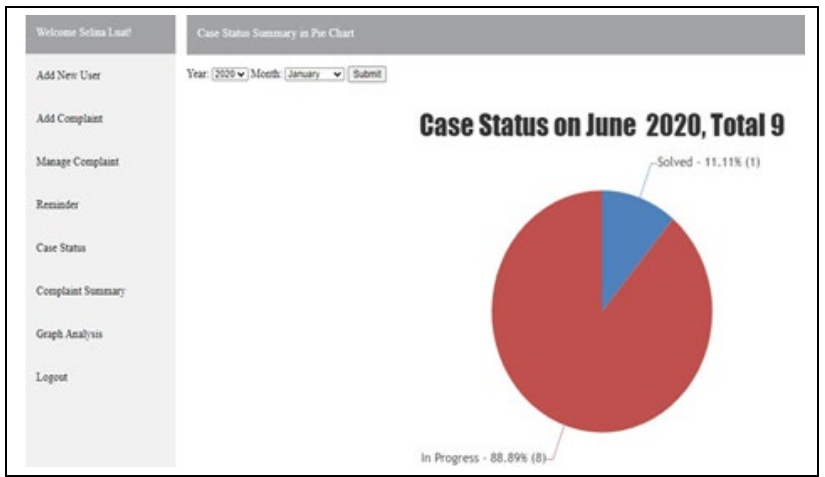

Figure 3. Information in graphical format - pie chart (Luat, 2020)

\begin{tabular}{|c|c|c|c|c|c|c|c|c|c|}
\hline 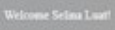 & \multicolumn{9}{|c|}{ Cosplenstansy } \\
\hline \multirow{2}{*}{ 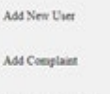 } & \multicolumn{9}{|c|}{ 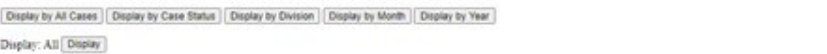 } \\
\hline & $x_{0}$ & Cas Number & Nome & Coveres Xuster & Datt & Aflerest Lecatioe & Dhisies & Conc Conezoy & Case Statos \\
\hline 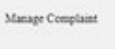 & 1 & CASEt & Evat & cot19:1679 & 200506.30 & Paderne & Koxhant & Went heverat & Sethes \\
\hline Renander & 2 & cases & Peess & $\cos 2867+12$ & 2005000.90 & $\sin A \operatorname{man}$ & $\sin \tan x$ & Were Quiry & in Progen \\
\hline Cane sata & 3 & CAsEt & Sout & cot116014355 & $200006-30$ & Andy: & smantans & $\operatorname{cosen}$ & m hopreat \\
\hline \multirow[t]{2}{*}{ Coenpluant Suanary } & 4 & casss & Matin: & consassiss & 202500.90 & Lora Baneg & Beseseg & 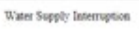 & in Proges \\
\hline & s & CAsto & Dris & cot197345: & $.000000 .-30$ & Bastagetex & 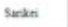 & Rox Sent Sentage Leak & In hopreat \\
\hline 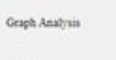 & - & case? & Let Ha & cosusert2s & 0000000000 & Sapai merat & $\sin$ & 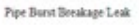 & in Rrogess \\
\hline \multirow{3}{*}{ Lepser } & ? & CASES & Anara & Cot7so74a: & 200000.30 & seag & Kopt & Wete hevaste & sin hoprest \\
\hline & 8 & casto & Pim Rewan & cosserrosi & $200006-30$ & Man & Maan & 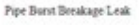 & in Propers \\
\hline & 3 & CASETO & Seta & C11978s612: & $.030060 .-30$ & $7 m$ & Butsto & Bingty nes Netert & shoprest \\
\hline
\end{tabular}

Figure 4. Complaint cases table (Luat, 2020)

If a user holds a position as Division Water Engineer, the system will navigate the user to Division Water Engineer's main page. Figure 5 shows the main page for Division Water Engineer which contains all the action that can be performed by the engineer. The Profile button will navigate user to the user profile page. The Update Complaint button will navigate the user to the update complaint page, the Notification button will navigate the user to the view notification page (Figure 6), the Case Status button will navigate the user to the case status page, 
the Complaint Summary will navigate the user to the complaint summary page and the Graph Analysis button will navigate the user to the graph and analysis page (Figure 7). The logout button on the top of the option will exit the user from the system.

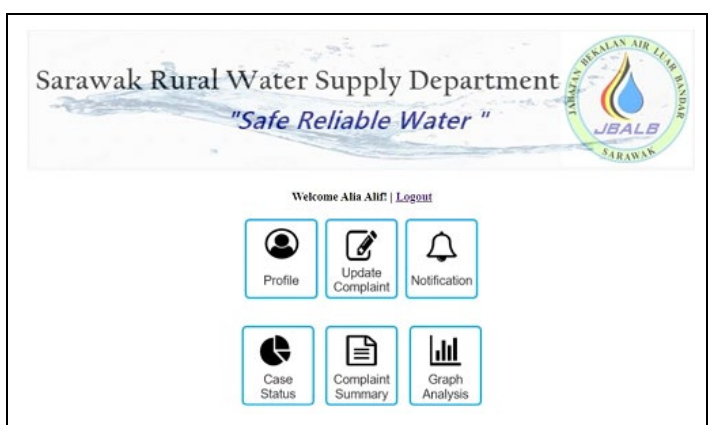

Figure 5. Main Page for Division Water Engineer (Luat, 2020)

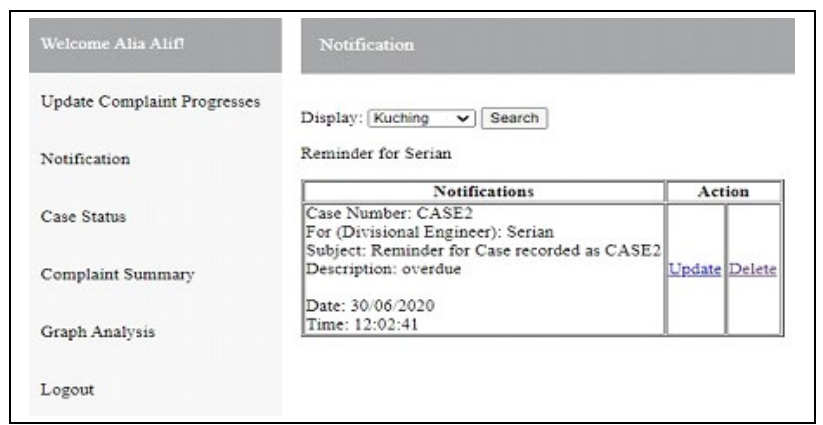

Figure 6. Reminder notification page for division water engineer (Luat, 2020)

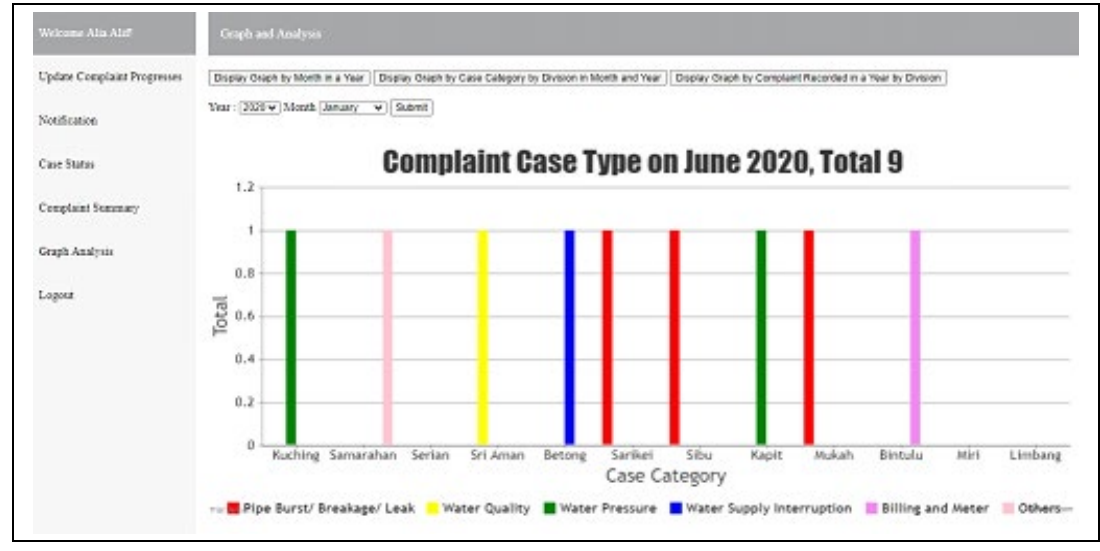

Figure 7. Total cases graph by division (Luat, 2020)

\section{DISCUSSION}

The Complaint Management System for Sarawak Rural Area Water Supply Department can be useful for staff in adding, viewing, updating, deleting and managing complaints. Besides, this system is also able to generate tables and graphs to summarize the complaints reported by division and month. Other than that, the system can also generate analysis for the progress of the complaints for every division by month using pie charts; it is also able to display a graphical analysis by division and month according to cases that were reported. Cases that are mentioned are pipe bursts, water quality, water pressure, water supply interruption, billing and meter. This system is also able to remind the engineers on their case progress so that issues will not be overlooked. With this system, cases that frequently happen at the same place can be studied to determine the cause and further improvements can be made. This system helps to improve the efficiency of the department in providing water supply.

User testing was carried out by asking five respondents who are staff (both administrative and engineer) of the Department to test the system and answer the questionnaire after testing the system. Users were asked to rate the system's design, functions, ease of use, reliability, and consistency. Users were also asked on whether they felt their current problems were solved, willingness to change to the new system, if they need assistance 
when using the system, ease of managing complaints workflow, and if they saved more time using the system as opposed to using the old manual way of managing complaints. A scale of 1-5 (1 being strongly disagree to 5 strongly agree) was used as rating. Responses given by users were mostly positive in the sense that most (more than three respondents) if not all users gave ratings of 3-5 for the questions asked. In addition to this, users were also asked to provide their suggestions to further improve this system in the future. Suggestions given were to have better instructions on how to use the system, as well as improve the interface design. From the results obtained, it can be concluded that the users were satisfied with the system and most importantly they felt that the system could help them to improve their work compared to the manual way of doing things.

\section{CONCLUSION}

Through this system, the Corporate Communication Unit staff and Division Water Engineer are able to record and manage complaints at any time. Problems that they faced before can be reduced through the use of this system. The most important role of this system is to track the area or any place that faces serious water supply problems so that the water supply at certain divisions can be investigated and improved. This will be a better web-based platform to manage complaints compared to the current way of manually doing the complaint management and using Microsoft Excel to create tables and graphs.

\section{ACKNOWLEDGEMENTS}

The authors would like to thank the Sarawak Rural Area Water Supply Department for the help and cooperation in carrying out this project.

\section{REFERENCES}

Luat, S. (2020). Complaint Management System for Sarawak Rural Area Water Supply Department. Kota Samarahan: Universiti Malaysia Sarawak.

Miller, N. (2018). 13 RAD Benefits, Including the Ones You Haven't Thought Of. Retrieved from https://kissflow.com/rad/benefits-of-rapid-application-development/

Sarawak Rural Water Supply Department (2020). The Official Website of Sarawak Rural Water Supply Department. Retrieved from https://jbalb.sarawak.gov.my/ 